\title{
Determinants and prevalence of early initiation of breastfeeding: Does the place of delivery matter? A comparative cross-sectional study based on the 2016 Ethiopian Demographic and Health Survey data
}

\author{
Kenbon Seyoum ${ }^{1}$, Yohannes Tekalegn ${ }^{2}$, Bruce J. E. Quisido ${ }^{3}$
}

\begin{abstract}
AFFILIATION
1 Department of Midwifery, School of Health Science, Goba Referral Hospital, Madda Walabu University, Goba, Ethiopia

2 Department of Public health, School of Health Science, Goba Referral Hospital, Madda Walabu University, Goba, Ethiopia

3 Department of Nursing, School of Health Science, Goba Referral Hospital, Madda Walabu University, Goba, Ethiopia
\end{abstract}

CORRESPONDENCE TO

Kenbon Seyoum. Department of Midwifery, School of Health Science,
Goba Referral Hospital, Madda Walabu University, P.O. Box: 207, Goba, Ethiopia. E-mail: kbseyoum8@gmail.com

\section{KEYWORDS}

children, infant, breastfeeding, early initiation, place of birth

Received: 29 June 2021

Revised: 25 November 2021

Accepted: 28 November 2021

https://doi.org/10.18332/popmed/144318 received prelacteal feedings $(A O R=0.25 ; 95 \%$ CI: $0.20-0.3)$, second/third birth orders (AOR=1.48; 95\% CI: 1.17-1.88) and fourth and above birth orders (AOR $=1.68$; 95\% CI: 1.25-2.24), large child size at birth (AOR=13.4; 95\% CI: $1.09-$ 1.65), and average birth size (AOR=1.7; 95\% CI: $1.14-1.65)$ and the administrative regions of the respondents, were significantly associated with early initiation of breastfeeding. CONCLUSIONS The proportion of EIBF among births at home and in the health facilities were the same. Statistically, children who were born in the health facilities were more likely to receive breast milk earlier. Not giving prelacteal feedings, birth orders two or more, average and large birth sizes, and respondents living in the administrative regions, were also associated with early initiation of breastfeeding.

ABBREVIATIONS ANC: antenatal care, EDHS: Ethiopian Demographic and Health Survey, EIBF: early initiation of breastfeeding, KR: kids record.

\section{INTRODUCTION}

World Health Organization (WHO) and United Nations Children's Fund (UNICEF) recommend that breastfeeding should be initiated within the first hour of birth, and should be continued without giving any kind of supplemental food and fluids ${ }^{1}$.

Both the mother and infant benefits from breastfeeding ${ }^{1}$. Breast milk contains all the nutrients a baby needs during his first six months of life ${ }^{2}$. Breast milk contains the best nutrients for infants; it is harmless, clean, and contains antibodies that protect the child from common childhood illnesses such as pneumonia and diarrhea. Reducing the risk of overweight and obesity during childhood is also a long-term health benefit of breastfeeding ${ }^{1,3}$. Breastfeeding improves cognitive development, and it reduces the risk for type 2 diabetes in children, moreover, it is important for the mothers because it prevents loss of blood, and furthermore it improves lactation ${ }^{4}$. It is the single most effective intervention for improving the survival and health of a child 5 .

Early initiation of breastfeeding is latching a newborn 
to a breast within the first hour of birth ${ }^{6}$. It is essential for child survival and long-term breastfeeding ${ }^{5}$. The first hours and days after birth are the most critical times for newborn survival, and delaying the initiation of breastfeeding places a baby at an increased risk of death ${ }^{7}$. Delaying the initiation of breastfeeding by 2-23 hours, and by 24 hours or more after birth, increases the risk of death by 40 and $80 \%$ in the first 28 days, respectively ${ }^{8}$. Early initiation of breastfeeding can avert neonatal death by about $33 \%{ }^{9}$, and reduces the rate of diarrheal phenomena by $26 \%{ }^{10}$. Early introduction of breast milk for the first six months of life prevents newborn and infant deaths by preventing infectious disease occurrence ${ }^{5}$. It reduces infant mortality by $22 \%{ }^{11}$, and moreover, increases the rate of exclusive breastfeeding practices ${ }^{8}$.

Globally, 78 million newborns in 2017 wait for over an hour to be latched on the breast for breast milk. It ranges from $65 \%$ in Eastern and Southern Africa to 32\% in East Asia and the Pacific ${ }^{12}$. The scale-up of breastfeeding could avert 823000 yearly deaths in children aged $<5$ years $^{13}, 20000$ yearly demises from breast cancer ${ }^{14}$, and reduction of the risk for ovarian cancers ${ }^{1}$. Globally, $80 \%$ of babies are fed with breast milk, but only $50 \%$ are fed within their first hour of birth $^{15}$. Studies from different African countries report a prevalence of EIBF that ranges from 41 to $87 \%{ }^{16,17}$, and a study conducted in different parts of Ethiopia reported that the prevalence of EIBF ranges from 39.6 to $83.7 \%{ }^{18,19}$.

Regarding the determinants of EIBF, previous studies found that the age of the respondents, educational level, income status of the family, modes of birth, parities, birth weights, neonatal resuscitations at birth, time of skin-toskin contact, residences, ANC visits, place of birth, number of births, birth intervals, birth sizes and marital status, were all associated with $\mathrm{EIBF}^{20,21}$.

In Ethiopia, several studies have been conducted on early initiation of breastfeeding. These studies showed that a significant number of children were still fed on the breasts one hour after their births. This study aimed to compare the status of early initiation of breastfeeding among home and health facility births, and the determinants of EIBF using the 2016 Ethiopian Demographic and Health Survey data.

\section{METHODS}

\section{Data source}

This study was based on the 2016 Ethiopian Demographic and Health Survey (EDHS) data. It was extracted from the kid's record (KR) file of the EDHS data set. The 2016 EDHS is the recent and the fourth Demographic and Health Survey implemented by the Central Statistical Agency (CSA) from 18 January to 27 June 2016. It is a nationally representative cross-sectional survey collected from all nine regions and two administrative cities ${ }^{6}$.

\section{Sampling procedures}

The 2016 EDHS used a two-stage stratified cluster sampling technique. The first stage was done by using the enumeration area (EA). This was perpetuated by stratifying the region into urban and rural areas, except for Addis Ababa city, and by using proportional allocation for each stratum. The second stage was done by listing the households among the selected enumeration $\operatorname{areas}^{6}$ ([Ethiopia], 2016 \#14596). This study used 10641 women's individual samples owning children aged $<5$ years. As per the guideline of DHS, this study used last born children under 24 months $^{22}$. Children who were never breastfed (575 observations), not last born, and children older than 24 months, were excluded from the study (6116 observations). Mothers who gave birth in the health facilities and home were kept for analysis, whereas, those whose place of birth was unknown, were excluded (60 observations). Summative results of this study were based on 4087 weighted samples after excluding children older than 24 months, were not breastfed, were not last born, and those with an unknown place of birth.

\section{Outcome variables}

Early initiation of breastfeeding is defined as the 'proportion of last born children under 24 months who were latched on the breast within the first hour of birth'6,23. Mothers were asked how long after birth they first put their newborn on their breasts. It is considered early if they latched the newborn to their breasts within the first hour of birth, otherwise initiation of breast feeding was considered late, these were coded as ' 0 ' if late, and ' 1 ' if early.

\section{Independent variables}

Independent variables include sociodemographic characteristics such as place of residence (urban or rural), mother's education level (no education, primary, secondary/ higher), mother currently working (yes or no), mother's age group (15-24, 25-34 or >34 years), marital status of the mother (never in a union, married and or living with a partner, widowed/divorced/separated), husband or partner's educational level (no education, primary, secondary/higher, and don't know), region (Tigray, Afar/Somali, Amhara, Oromia,, Gambela/Benishangul, SNNPR, Metropolitan cities [Addis Ababa, Harari and Dire Dawa]), religion (Christian, Muslim, and other traditional), exposure to mass media (with exposure or without exposure), and wealth index (poor, middle, rich). Details on wealth index calculation can be found on $\mathrm{DHS}^{6}$. Other independent variables are obstetric characteristics of the mothers such as place of birth (home or health facility), number of antenatal care visits (ANC) (no ANC, 1-3 visits, or $\geq 4$ ), contraceptive use (yes or no), birth order of the child (first, second/third, or $\geq 4$ ), and size of child at birth as (large, average, small, don't know). Regarding the place of birth, mothers who gave birth in either a private or government health institution were recoded as 'health facility', while the remaining as 'home'.

\section{Statistical analysis}

To manage sampling error and non-responses, a sampling 
weight was applied in all statistical analyses. Descriptive statistics were employed to describe the sociodemographic and obstetric characteristics of the mothers. Bivariate and multivariate logistic regression analysis was used to determine the association between the dependent and independent variables. Variables with a $\mathrm{p}<0.2$ during bivariate logistic regression, were retained for multivariate logistic regression analysis. Variables with a $p<0.05$ in the multivariate logistic regression analysis were finally used to declare statistical significances. Both crude and adjusted odds ratios are reported with 95\% confidence intervals $(95 \%$ CI). Stata version 14.0 was used for both descriptive and analytical analysis. Variance inflation factor was done to check for the presence of multicollinearity.

\section{RESULTS}

\section{Sociodemographic characteristics of mothers}

A total of 4087 weighted samples of breastfeeding mothers with last born children under 24 months were included in the analysis. In all, 2574 (63\%) gave birth at home, whereas 1513 (37 \%) gave birth in the health facilities. Regarding the age of the mothers, 1328 (51.6\%) among the home births and $763(50.4 \%)$ among the health facilities births were in the age group of 25-34 years. In terms of marital status of the mothers, 2472 (96.0\%) among the home births and 1429 (94.4\%) among the health facilities births, were married and living with their partners. Regarding the religion of the mothers, 1277 (49.6\%) and 996 (65.9\%) were Christians, for home and health facility births, respectively. In terms of place of residence and educational level of the mothers, 2525 (98.1\%) and 1863 (72.4\%) among the home births, and 1061 (70.6\%) and 599 (39.6\%) among the births in the health facilities, were from the rural areas and never had formal education. Concerning the husbands' educational status, 1011 (40.9\%) among their partners who gave birth at home, never attended school, and 570 (39.9\%) of the partners of those who gave birth in the health facilities, attended only primary education. Lastly, regarding the wealth indices, 1452 (56.4\%) of the mothers who gave birth at home, and 404 (26.7\%) of mothers whom gave birth in the health facilities, were poor (Table 1).

\section{Obstetric characteristics of mothers}

In all, $1959(76.1 \%)$ of the mothers who gave birth at home and 1150 (76\%) of mothers who gave birth in the health facilities, initiated early breastfeeding. Regarding the number of ANC visits, 1272 (49.4\%) and 150 (9.9\%) among mothers who gave birth at home and in the health facilities, respectively, did not have any ANC visits. Concerning contraceptive use, $2068(80.4 \%)$ among the mothers who gave birth at home and 830 (54.9\%) among mothers who gave birth in the health facilities, did not use any methods of contraception. A total of 1497 (58.2\%) among the home births and 511 (33.8\%) among the health facilities births had more than four birth orders. Regarding the sizes of the babies
Table 1. Sociodemographic characteristics of the mothers, further analysis of the 2016 Ethiopian Demographic and Health Survey, Ethiopia 2021 ( $N=4087$ )

\begin{tabular}{|c|c|c|}
\hline \multirow{2}{*}{ Variable } & \multicolumn{2}{|c|}{ Place of birth } \\
\hline & $\begin{array}{l}\text { Home } \\
\text { n (\%) }\end{array}$ & $\begin{array}{c}\text { Health } \\
\text { facility } \\
\text { n (\%) }\end{array}$ \\
\hline \multicolumn{3}{|l|}{ Mother's age (years) } \\
\hline $15-24$ & $683(26.5)$ & $506(33.4)$ \\
\hline $25-34$ & $1328(51.6)$ & $763(50.4)$ \\
\hline$>34$ & $563(21.9)$ & $244(16.2)$ \\
\hline \multicolumn{3}{|l|}{ Marital status } \\
\hline Never in union & $7(0.3)$ & $22(1.5)$ \\
\hline Married/living with a partner & $2472(96.0)$ & $1428(94.4)$ \\
\hline Widowed/divorced/separated & $95(3.7)$ & $63(4.1)$ \\
\hline \multicolumn{3}{|l|}{ Religion } \\
\hline Christian & $1277(49.6)$ & $996(65.9)$ \\
\hline Muslim & $1202(46.7)$ & $509(33.6)$ \\
\hline Traditional and other & $95(3.7)$ & $8(0.5)$ \\
\hline \multicolumn{3}{|l|}{ Place of residence } \\
\hline Urban & $49(1.9)$ & $444(29.4)$ \\
\hline Rural & $2525(98.1)$ & $1069(70.6)$ \\
\hline \multicolumn{3}{|l|}{ Mother's education level } \\
\hline No education & $1863(72.4)$ & $599(39.6)$ \\
\hline Primary & $662(25.7)$ & $597(39.4)$ \\
\hline Secondary and above & $49(1.9)$ & $317(30.0)$ \\
\hline \multicolumn{3}{|l|}{ Husband's education level } \\
\hline No education & $1315(53.2)$ & $413(28.9)$ \\
\hline Primary & $1011(40.9)$ & $570(39.9)$ \\
\hline Secondary and above & $131(5.3)$ & $438(30.7)$ \\
\hline Don't know & $17(0.6)$ & $8(0.5)$ \\
\hline \multicolumn{3}{|l|}{ Currently working } \\
\hline No & 2025 (78.7) & $1043(68.9)$ \\
\hline Yes & $549(21.3)$ & $470(31.1)$ \\
\hline \multicolumn{3}{|l|}{ Mass media exposure } \\
\hline No exposure & 1927 (74.9) & $742(49.1)$ \\
\hline Exposure & $647(25.1)$ & $771(50.9)$ \\
\hline \multicolumn{3}{|l|}{ Wealth index } \\
\hline Poor & $1452(56.4)$ & $404(26.7)$ \\
\hline Middle & $562(21.8)$ & $279(18.4)$ \\
\hline Rich & $560(21.8)$ & $830(59.54 .9)$ \\
\hline \multicolumn{3}{|l|}{ Region } \\
\hline Tigray & $79(3.1)$ & $219(14.5)$ \\
\hline Afar and Somali & $164(6.4)$ & $47(3.1)$ \\
\hline Amhara & $465(18.1)$ & $285(18.9)$ \\
\hline Oromia & $1324(51.4)$ & $494(32.6)$ \\
\hline Benishangul and Gambela & $33(1.3)$ & $20(1.3)$ \\
\hline SNNPR & $497(19.3)$ & $326(21.6)$ \\
\hline Metropolitan cities & $12(0.5)$ & $122(8.0)$ \\
\hline
\end{tabular}


at birth, 1030 (40.0\%) born at home and 642 (42.5\%) born in the health facilities, were subjectively reported by their mothers as of average size. Of 2360 (91.7\%) mothers who gave birth at home and of 1403 (92.8\%) among those who gave birth in the health facilities, were not provided with prelacteal feedings (Table 2).

Factors associated with early initiation of breastfeeding After controlling for confounders in multivariate logistic regression analysis, prelacteal feedings, place of birth, birth orders, size of child at birth, and the administrative region, were found to be significantly associated with early initiations of breastfeeding.

A child who received prelacteal feeding had $75 \%$ (AOR $=0.25$; 95\% CI: $0.20-0.3$ ) lower odds of early initiation of breastfeeding. Mothers who gave birth at a health facility had 1.30 times (AOR=1.30; 95\% CI: 1.06-1.61) higher odds of early initiation of breastfeeding. The second/third birth orders, and fourth/above birth orders had $48 \%$ (AOR=1.48; 95\% CI: $1.17-1.88$ ) and 68\% (AOR=1.68; 95\% CI: $1.25-2.24$ ) higher odds of early initiation of breastfeeding. A mother with large or average child size at birth had 1.34 (AOR=13.4; 95\% CI: 1.09-1.65) and 1.37 (AOR=1.7; 95\% CI: 1.14-1.65) times higher odds of early initiation of breastfeeding, respectively. Mothers from the Oromia region $(\mathrm{AOR}=2.34$; 95\% CI: 1.70-3.21), Afar/Somali (AOR=1.82; 95\% CI: 1.342.47) and Benishangul/Gambela region (AOR $=1.72$; $95 \% \mathrm{CI}$ : 1.27-2.34) were $2.34,1.82$ and 1.72 times more likely to start early initiation of breastfeeding, respectively, compared to mothers living in the Tigray region. Mothers living in SNNPR were 2.47 times more likely (AOR=2.47; 95\% CI: $1.80-3.44$ ), as well. Finally, mothers from metropolitan cities $(\mathrm{AOR}=4.40$; 95\% CI: 3.12-6.15) were 4.4 times more likely to start early initiation of breastfeeding compared to mothers from Tigray region (Table 3).
Table 2. Obstetric characteristics of the mothers with their children under 2 years, a comparison by place of birth, further analysis of the 2016 Ethiopian Demographic and Health Survey, Ethiopia 2021 (N=4087)

\begin{tabular}{|c|c|c|}
\hline \multirow[t]{2}{*}{ Characteristics } & \multicolumn{2}{|c|}{ Place of birth } \\
\hline & $\begin{array}{l}\text { Home } \\
\text { n (\%) }\end{array}$ & $\begin{array}{c}\text { Health } \\
\text { facility } \\
\text { n (\%) }\end{array}$ \\
\hline \multicolumn{3}{|c|}{ Initiation of breastfeeding } \\
\hline Late & $615(23.9)$ & $363(24.0)$ \\
\hline Early & 1959 (76.1) & $1150(76.0)$ \\
\hline \multicolumn{3}{|c|}{ Number of ANC visits } \\
\hline 0 & $1272(49.4)$ & $150(9.9)$ \\
\hline $1-3$ & 801 (31.1) & $494(32.7)$ \\
\hline$\geq 4$ & 501 (19.5) & $869(57.4)$ \\
\hline \multicolumn{3}{|c|}{ Contraceptive use } \\
\hline No & $2068(80.4)$ & $830(54.9)$ \\
\hline Yes & $506(19.6)$ & $683(45.1)$ \\
\hline \multicolumn{3}{|l|}{ Birth order } \\
\hline First & $332(12.9)$ & $504(33.3)$ \\
\hline Second or third & $745(28.9)$ & $498(32.9)$ \\
\hline Fourth or more & $1497(58.2)$ & $511(33.8)$ \\
\hline \multicolumn{3}{|l|}{ Birth size } \\
\hline Large & 717 (27.9) & $482(31.9)$ \\
\hline Average & $1030(40.0)$ & $643(42.5)$ \\
\hline Small & $800(31.1)$ & $376(24.9)$ \\
\hline Don't know & $27(1.0)$ & $12(0.4)$ \\
\hline \multicolumn{3}{|c|}{ Prelacteal feeding } \\
\hline No & 2360 (91.7) & $1403(92.8)$ \\
\hline Yes & $214(8.3)$ & $110(7.2)$ \\
\hline
\end{tabular}

Table 3. Factors associated with early initiation of breastfeeding, further analysis of the 2016 Ethiopian Demographic and Health Survey, Ethiopia 2021 (N=4087)

\begin{tabular}{|c|c|c|c|c|}
\hline \multirow[t]{2}{*}{ Variables } & \multicolumn{2}{|c|}{ Initiation of breastfeeding } & \multirow[t]{2}{*}{ OR (95\% CI) } & \multirow[t]{2}{*}{ AOR $(95 \%$ CI $)$} \\
\hline & Late $\mathbf{n}$ & Early n & & \\
\hline \multicolumn{5}{|l|}{ Place of birth } \\
\hline Home & 615 & 1959 & 1 & \\
\hline Health facility & 363 & 1150 & $1.35(1.17-1.57)$ & $1.30(1.06-1.61)^{*}$ \\
\hline \multicolumn{5}{|l|}{ Birth size } \\
\hline Small & 331 & 845 & 1 & 1 \\
\hline Large & 264 & 936 & $1.61(1.34-1.94)$ & $1.34(1.09-1.65)$ \\
\hline Average & 374 & 1298 & $1.58(1.34-1.87)$ & $1.37(1.14-1.65)$ \\
\hline Don't know & 9 & 30 & $1.55(0.75-3.20)$ & $1.40(0.61-3.19)$ \\
\hline \multicolumn{5}{|c|}{ Place of residence } \\
\hline Urban & 116 & 377 & 1 & 1 \\
\hline Rural & 862 & 2732 & $0.70(0.59-0.86)$ & $0.89(0.66-1.20)$ \\
\hline
\end{tabular}


Table 3. Continued

\begin{tabular}{|c|c|c|c|c|}
\hline \multirow[t]{2}{*}{ Variables } & \multicolumn{2}{|c|}{ Initiation of breastfeeding } & \multirow[t]{2}{*}{ OR $(95 \% \mathrm{CI})$} & \multirow[t]{2}{*}{ AOR $(95 \% \mathrm{CI})$} \\
\hline & Late $\mathbf{n}$ & Early n & & \\
\hline \multicolumn{5}{|l|}{ Mother's education level } \\
\hline No education & 580 & 1882 & 1 & 1 \\
\hline Primary & 298 & 961 & $1.17(0.99-1.38)$ & $1.01(0.82-1.26)$ \\
\hline Secondary and above & 100 & 266 & $1.20(0.96-1.51)$ & $1.01(0.72-1.42)$ \\
\hline \multicolumn{5}{|l|}{ Mother's age (years) } \\
\hline $15-24$ & 306 & 883 & 1 & 1 \\
\hline $25-34$ & 455 & 1636 & $1.17(0.99-1.37)$ & $0.91(0.72-1.14)$ \\
\hline$>34$ & 217 & 590 & $1.14(0.93-1.40)$ & $0.89(0.66-1.21)$ \\
\hline \multicolumn{5}{|l|}{ Prelacteal feed } \\
\hline No & 825 & 2938 & 1 & 1 \\
\hline Yes & 153 & 171 & $0.27(0.23-0.32)$ & $0.25(0.20-0.31)$ \\
\hline \multicolumn{5}{|l|}{ Husband's education level } \\
\hline No education & 432 & 1295 & 1 & 1 \\
\hline Primary & 340 & 1241 & $1.30(1.10-1.54)$ & $0.98(0.81-1.20)$ \\
\hline Secondary and above & 143 & 425 & $1.31(1.08-1.60)$ & $0.99(0.76-1.32)$ \\
\hline Don't know & 12 & 13 & $0.54(0.26-1.13)$ & $0.56(0.26-1.21)$ \\
\hline \multicolumn{5}{|l|}{ Number of ANC } \\
\hline 0 & 306 & 1116 & 1 & 1 \\
\hline $1-3$ & 331 & 964 & $1.06(0.89-1.27)$ & $0.91(0.74-1.12)$ \\
\hline$\geq 4$ & 341 & 1029 & $1.15(0.97-1.36)$ & $0.79(0.63-0.99)$ \\
\hline \multicolumn{5}{|l|}{ Mass media exposure } \\
\hline No exposure & 640 & 2030 & 1 & 1 \\
\hline Exposure & 338 & 1079 & $1.14(0.98-1.33)$ & $0.86(0.74-1.04)$ \\
\hline \multicolumn{5}{|l|}{ Contraceptive use } \\
\hline No & 694 & 2204 & 1 & 1 \\
\hline Yes & 284 & 905 & $1.23(1.04-1.45)$ & $0.98(0.80-1.20)$ \\
\hline \multicolumn{5}{|l|}{ Wealth index } \\
\hline Poor & 427 & 1429 & 1 & 1 \\
\hline Middle & 202 & 639 & $1.41(1.14-1.77)$ & $1.16(0.90-1.48)$ \\
\hline Rich & 349 & 1041 & $1.49(1.27-1.75)$ & $1.18(0.92-1.51)$ \\
\hline \multicolumn{5}{|l|}{ Birth order } \\
\hline First & 256 & 580 & 1 & 1 \\
\hline Second or third & 259 & 983 & $1.40(1.15-1.70)$ & 1.48 (1.17-1.88)* \\
\hline Fourth and above & 463 & 1546 & $1.29(1.08-1.58)$ & $1.68(1.25-2.24)^{*}$ \\
\hline \multicolumn{5}{|l|}{ Regional states } \\
\hline Tigray & 104 & 194 & 1 & 1 \\
\hline Afar and Somali & 54 & 157 & $0.98(0.77-1.26)$ & $1.82(1.34-2.47)$ \\
\hline Amhara & 238 & 512 & $1.18(0.88-1.59)$ & $1.32(0.96-1.84)$ \\
\hline Oromia & 370 & 1448 & $2.21(1.66-2.93)$ & $2.34(1.70-3.21)^{*}$ \\
\hline Benishangul and Gambela & 15 & 39 & $1.59(1.21-2.09)$ & $1.72(1.27-2.34)^{*}$ \\
\hline SNNPR & 163 & 660 & $2.28(1.68-3.09)$ & $2.47(1.80-3.44)^{*}$ \\
\hline Metropolitan cities & 34 & 99 & $3.10(2.31-4.17)$ & $4.40(3.12-6.15)^{*}$ \\
\hline
\end{tabular}

All variables in the table were taken to multivariate logistic regression to adjust for confounding. Bold variables were found to be significantly associated with early initiation of breastfeeding. OR: odds ratio. AOR: adjusted odds ratio. CI: confidence interval. *Variables with p<0.05 in multivariate analysis. 


\section{DISCUSSION}

The Ethiopian Federal Ministry of Health - family health department - advised that all children should start breastfeeding within the first hour of birth, which should be continued exclusively for the first 6 months of life ${ }^{2}$. This study provides information on the determinants of early initiation of breastfeeding and also attempts to compare its prevalence by the place of birth among mothers with index children of $<24$ months residing in Ethiopia. The prevalence of early initiation of breastfeeding among home births was $76.1 \%$ and among health facility births was $76.0 \%$. This study indicates that the proportion of early initiation of breastfeeding is not affected by the place of birth. This is supported by a report from UNICEF, that the rate of early initiation of breastfeeding does not vary by the place of birth ${ }^{7}$. The prevalence in this study was higher than those of studies conducted in Tanzania ${ }^{24}$, Uganda $^{25}$, and Burkina Faso ${ }^{17,26}$, but lower than those of studies conducted in Nigeria ${ }^{27}$ and Southern Ethiopia ${ }^{19}$. These differences may be due to variations in maternal sociodemographic characteristics, and in sociocultural, economical, and health service utilization characteristics between the respondents of the reference and study areas. The prevalence of early initiation of breastfeeding in this study is consistent with the studies conducted in Debre Tabor $^{28}$, and Dembecha ${ }^{29}$, but higher than those of studies conducted in Amibara ${ }^{18}$, and Tigray ${ }^{30}$. These discrepancies may be related to misunderstandings about early feedings of breast milk, cultural differences between the communities, and differences in sample size.

Women who gave birth in healthcare facilities were more likely to initiate early breast feeding. This is consistent with the studies conducted in the Gurage Zone (Ethiopia) ${ }^{20}$, and a study in 30 Sub-Saharan African countries ${ }^{31}$. This might be due to giving birth in the health facilities gives mothers better opportunities in obtaining professional advice regarding the benefits of early initiation of breastfeeding for their babies. Births in the health facilities do not only provide information to the parturient, but moreover, gives them information about contesting perceived cultural norms and customs that will hinder them from putting their babies to access breast milk. The other possible explanation is the notion that practices of prelacteal feedings among mothers giving birth at home are common but they negatively affect the early initiation of breastfeeding. This is supported by a study conducted in Ethiopia ${ }^{32}$.

This study has found that mothers who provided prelacteal feedings had $75 \%$ lower odds of early initiation of breast milk. This finding is consistent with studies conducted in Ethiopia and Saudi Arabia ${ }^{33,34}$. This may be due to the fact that prelacteal feeding is the norm in certain communities ${ }^{35}$. The other possible explanation might be that mothers who have started late in the initiation of breastfeeding have misconceptions and cultural malpractices on newborn feedings. The explanation is that the provision of prelacteal feedings fill the neonates' stomachs thus reducing their interest on suckling, in turn, this delays breast milk secretion and lengthens the time of initiation of breastfeeding.

Birth orders were also significantly associated with early initiation of breastfeeding. Being the second birth and above, was also more likely to start early initiation of breastfeeding compared to first births. This could be related to the experiences of mothers with previous births. The knowledge or awareness of mothers regarding the benefits of breastfeeding may increase with birth experience. As birth experience increases, the chance of visiting health institutions will also increase, which in turn increases the mothers' knowledge about the benefits of breastfeeding. This finding is consistent with the studies conducted in Namibia ${ }^{21}$ and Amibara Northeastern Ethiopia ${ }^{18}$.

Birth sizes of children were significantly associated with EIBF. This is similar to the study done Namibia ${ }^{21}$. This can be due to the fact that small babies have weak suckling reflexes and difficulty swallowing, owing to prematurity ${ }^{21}$.

Early initiation of breastfeeding was also significantly associated with the region of residence, though the distributions are widely different. The odds of practicing early initiation of breastfeeding among the residents of Benishangul/Gambela regions were 1.72 times higher compared to those mothers living in Tigray region. Those living in Afar/Somali regions were also 1.82 times more likely to start early initiations of breastfeeding. Additionally, mothers from SNNPR and Oromia are 2.34 and 2.47 times more likely to practice early breastfeeding, respectively. This may be attributed to differences in availability and access to healthcare services. The odds of early initiation of breastfeeding were 4.40 times higher in the metropolitan cities (Addis Ababa, Harari and Dire Dawa) compared to the Tigray region. The possible explanation is that the residents of the metropolitan cities are entirely urbanized. This helps easy access to media, health facilities, and health education. The better infrastructures in the urban areas positively affect the access to health facilities.

\section{Strengths and limitations}

Among the strengths of this study are the use of a large, nationally representative sample size, and collection of data used structured and validated tools. The limitations of this study are the increased chance for recall bias while collecting the data from the mothers who have children aged $<24$ months and the cross-sectional design giving the associations only and not correlations.

\section{CONCLUSIONS}

Children who were born in the health facilities were more likely to commence early initiation of breastfeeding than those born at home. Prelacteal feedings, birth orders, sizes of children at birth, and administrative regions, were associated with early initiation of breastfeeding. Mothers are encouraged to give birth in the health facilities, and 
awareness creation regarding optimal feedings of children are recommended for all pregnant women. Community based education may help to improve the rates of early initiation of breastfeeding among mothers giving birth at home. This can be achieved through at home lessons regarding the benefits of early initiation of breastfeeding by health extension workers.

\section{REFERENCES}

1. Breastfeeding. World Health Organisation. Accessed July 27, 2020. https://www.who.int/health-topics / breastfeeding\#tab=tab_1

2. NATIONAL STRATEGY FOR INFANT AND YOUNG CHILD FEEDING. Federal Ministry of Health, Family Health Department Ethiopia; 2004. April 2004. Accessed November 25, 2021. https://motherchildnutrition.org/nutritionprotection-promotion/pdf/mcn-national-strategy-for-infantand-young-child-feeding-ethiopia.pdf

3. Early initiation of breastfeeding to promote exclusive breastfeeding. World Health Organization. Updated February 11, 2019. Accessed July 23, 2020. https://www.who.int/ elena/titles/early_breastfeeding/en/

4. Paddock C. Why Breastfeeding In The First Hour Of Life Is Important. Medical News Today. August 1, 2007. Accessed July 23, 2020. https://www.medicalnewstoday.com/ articles/78485\#1

5. Lutter C. Early Initiation of Breastfeeding: the Key to Survival and Beyond. Pan American Health Organization; 2010. Accessed August 3, 2020. https://www.paho.org/hq/ dmdocuments /2010/Technical\%20brief.\%20Early\%20 initiation\%20 of\%20 breastfeeding.\%20The \%20 key\%20 to $\% 20$ survival $\% 20$ and $\% 20$ beyond.pdf

6. Central Statistical Agency, ICF International. ETHIOPIA Demographic and Health Survey 2016. CSA, ICF International; 2017. Accessed November 25, 2021. https:// dhsprogram.com/pubs/pdf/FR328/FR328.pdf

7. UNICEF, World Health Organization. Capture the Moment - Early initiation of breastfeeding: The best start for every newborn. UNICEF, World Health Organization; 2018. Accessed November 25, 2021. https://www.unicef.org/eca/ media/4256/file/Capture-the-moment-EIBF-report.pdf

8. NEOVITA Study Group. Timing of initiation, patterns of breastfeeding, and infant survival: prospective analysis of pooled data from three randomised trials. Lancet Glob Health. 2016;4(4):e266-e275. doi:10.1016/S2214-109X(16)00040-1

9. Mugadza G, Zvinavashe M, Gumbo FZ, Pedersen BS. Early breastfeeding initiation and incidence of neonatal sepsis in Chipinge District Zimbabwe. Int J Contemp Pediatrics. 2018;5(1):1-5. doi:10.18203/2349-3291.ijcp20175564

10. Clemens J, Elyazeed RA, Rao M, et al. Early Initiation of Breastfeeding and the Risk of Infant Diarrhea inRural Egypt. Pediatrics. 1999;104(1):e3. doi:10.1542/peds.104.1.e3

11. Early Initiation of Breastfeeding (IMD) Reducing infant mortality by 22 Percent. IPB University. December 28,
2010. Accessed July 23, 2020. https://www.ipb.ac.id/ news/index/2010/12/early-initiation-of-breastfeedingimd-reducing-infant-mortality-by-2 2 -percent / ad0f55ca62403dd959e35d9647885344

12. Friedrich MJ. Early Initiation of Breastfeeding. JAMA. 2018;320(11):1097. doi:10.1001/jama.2018.13372

13. World Health Organization, UNICEF. GLOBAL BREASTFEEDING SCORECARD, 2017: Tracking Progress for Breastfeeding Policies and Programmes. World Health Organization, Unicef; 2017. Accessed August 4, 2020. https://www.who.int/nutrition/publications/infantfeeding/ global-bf-scorecard-2017.pdf?ua=1

14. Victora CG, Bahl R, Barros AJD, et al. Breastfeeding in the 21st century: epidemiology, mechanisms, and lifelong effect. Lancet. 2016;387(10017):475-490. doi:10.1016/S0140-6736(15)01024-7

15. United Nations Children's Fund. BREASTFEEDING: A Mother's Gift, for Every Child. UNICEF; 2018. https://data. unicef.org/resources/breastfeeding-a-mothers-gift-forevery-child/

16. Smith ER, Locks LM, Manji KP, et al. Delayed Breastfeeding Initiation Is Associated with Infant Morbidity. J Pediatr. 2017;191:57-62.e2. doi:10.1016/j.jpeds.2017.08.069

17. Savadogo LGB, Ilboudo B, Meda C, Kinda M. Early Initiation of Breastfeeding and Its Association in Rural Areas of Burkina Faso. Open J Epidemiol. 2018;8(2):54-66. doi:10.4236/ojepi.2018.82005

18. Liben ML, Yesuf EM. Determinants of early initiation of breastfeeding in Amibara district, Northeastern Ethiopia: a community based cross-sectional study. Int Breastfeed J. 2016;11:7. doi:10.1186/s13006-016-0067-8

19. Beyene MG, Geda NR, Habtewold TD, Assen ZM. Early initiation of breastfeeding among mothers of children under the age of 24 months in Southern Ethiopia. Int Breastfeed J. 2017;12:1. doi:10.1186/s13006-016-0096-3

20. Shiferaw BZ, Mossa KA, Gashaw BT. Factors Associated with Early Initiation and Exclusive Breastfeeding Practices among Mothers of Infant's Age Less Than 6 Months. J Pediatr Neonatal Care. 2017;7(3):00292. doi:10.15406/jpnc.2017.07.00292

21. Ndirangu MN, Gatimu SM, Mwinyi HM, Kibiwott DC. Trends and factors associated with early initiation of breastfeeding in Namibia: analysis of the Demographic and Health Surveys 2000-2013. BMC Pregnancy Childbirth. 2018;18(1):171. doi:10.1186/s12884-018-1811-4

22. Croft TN, Marshall AMJ, Allen CK. Guide to DHS Statistics. ICF; 2018. Accessed November 25, 2021. https://www. dhsprogram.com/pubs/pdf/DHSG1/Guide_to_DHS_ Statistics_DHS-7.pdf

23. World Health Organization. Indicators for assessing infant and young child feeding practices: Part 1 Definitions. World Health Organization; 2008. Accessed November 25, 2021. https://www.unhcr.org/4b752d509.pdf

24. Exavery A, Kanté AM, Hingora A, Phillips JF. Determinants of early initiation of breastfeeding in rural Tanzania. Int 
Breastfeed J. 2015;10:27. doi:10.1186/s13006-015-0052-7

25. Bbaale E. Determinants of Early Initiation, Exclusiveness, and Duration of Breastfeeding in Uganda. J Health Popul Nutr. 2014;32(2):249-260. Accessed November 25, 2021. https:// www.ncbi.nlm.nih.gov/pmc/articles/PMC4216961/pdf/ jhpn0032-0249.pdf

26. Acharya S, Khanal C, Dahal AS, Maharjan M, Bhandari B. The Determinants of Early Initiation of Breastfeeding Practice among Mothers Attending a Tertiary Hospital, Kathmandu. NEPAS journal : a Nepal Paediatric Society journal. 2019;39(3):168-173. doi:10.3126/jnps.v39i3.24909

27. Kelechi-Ebisike VO, Solomon MD, Jaryum KH, Ebisike KJ, Danjin M. Prevalence of Early Initiation of Breastfeeding (EIBF) and Exclusive Breastfeeding (EBF) and Some Associated Factors among Mothers in Gombe Metropolis, Gombe State, Nigeria. Acta Scientific Nutritional Health. 2020;4(1):130-135. doi:10.31080/ASNH.2020.04.0586

28. Abie BM, Goshu YA. Early initiation of breastfeeding and colostrum feeding among mothers of children aged less than 24 months in Debre Tabor, northwest Ethiopia: a cross-sectional study. BMC Res Notes. 2019;12(1):65. doi:10.1186/s13104-019-4094-6

29. Bimerew A, Teshome M, Kassa GM. Prevalence of timely breastfeeding initiation and associated factors in Dembecha district, North West Ethiopia: a cross-sectional study. Int Breastfeed J. 2016;11(1):28. doi:10.1186/s13006-016-0087-4

30. Gebremeskel SG, Gebru TT, Gebrehiwot BG, et al. Early initiation of breastfeeding and associated factors among mothers of aged less than 12 months children in rural eastern zone, Tigray, Ethiopia: cross-sectional study. BMC Res Notes. 2019;12(1):671. doi:10.1186/s13104-019-4718-x

31. Bergamaschi N, Oakley L, Benova L. Is childbirth location associated with higher rates of favourable early breastfeeding practices in Sub-Saharan Africa? J Glob Health. 2019;9(1):010417. doi:10.7189/jogh.09.010417

32. Legesse M, Demena M, Mesfin F, Haile D. Prelacteal feeding practices and associated factors among mothers of children aged less than 24 months in Raya Kobo district, North Eastern Ethiopia: a cross-sectional study. Int Breastfeed J. 2014;9(1):189. doi:10.1186/s13006-014-0025-2

33. Argaw MD, Asfaw MM, Ayalew MB, et al. Factors associated with prelacteal feeding practices in Debre Berhan district, North Shoa, Central Ethiopia: a cross-sectional,

\section{CONFLICTS OF INTEREST}

The authors have completed and submitted the ICMJE Form for Disclosure of Potential Conflicts of Interest and none was reported.

FUNDING

There was no source of funding for this research.

ETHICAL APPROVAL AND INFORMED CONSENT

Ethical approval and informed consent were not required for this study, as the study used secondary data which were received after obtaining permission from https://www.dhsprogram.com. There were no identified names of individuals or household addresses in the data files. community-based study. BMC Nutrition. 2019;5(1):14. doi:10.1186/s40795-019-0277-8

34. El-Gilany AH, Sarraf B, Al-Wehady A. Factors associated with timely initiation of breastfeeding in Al-Hassa province, Saudi Arabia. East Mediterr Health J. 2012;18(3):250-254. doi:10.26719/2012.18.3.250

35. Dashti M, Scott JA, Edwards CA, Al-Sughayer M. Determinants of breastfeeding initiation among mothers in Kuwait. Int Breastfeed J. 2010;5(1):7. doi:10.1186/1746-4358-5-7 